\title{
İç Isı Değiştiricili Bir Organik Rankin Çevriminin Enerji ve Ekserji Analizi
}

\author{
Arzu ŞENCAN ŞAHIN ${ }^{(D)}{ }^{*}$, Cihanşah AĞ ${ }^{(D)}$, Osman ÖZYURT ${ }^{(D)} 1$, Yasin ASLAN (D) 1 \\ ${ }^{1}$ Isparta Uygulamalı Bilimler Üniversitesi, Teknoloji Fakültesi, Isparta \\ Geliş Tarihi (Received): 26.10.2020, Kabul Tarihi (Accepted): 02.02.2021 \\ $\square$ Sorumlu Yazar (Corresponding author*): arzusencan@isparta.edu.tr \\ (C) +902462146772 氞 +902462146899
}

ÖZ

Bu çalışmada R1234yf, R1234ze ve R134a çalışma akışkanlarının kullanıldığı iç ısı değiştiricili bir Organik Rankine Çevriminin (ORC) enerji ve ekserji analizi yapılmıştır. Farklı çalışma sıcaklıkları için ORC sisteminin enerji ve ekserji performansları analiz edilmiştir. Yapılan analizden kazan, yoğuşturucu ve aşırı soğutma sıcaklıklarının hem enerji hem de ekserji verimlerini önemli derecede etkilediği görülmüştür. Kazan ve aşırı soğutma sıcaklığının artmasıyla enerji ve ekserji verimlerinin arttığı, yoğuşturucu sıcaklığının artmasıyla enerji ve ekserji verimlerinin azaldığı görülmüştür. Ayrıca her bir elemana ait ekserji yıkımları belirlenmiştir. Türbin ve pompa izentropik kabul edildiği için bu elemanlardaki ekserji yıkımları ihmal edilmiştir. En fazla ekerji yıkımının \%72 oranında yoğuşturucuda, en düşük ekserji yıkımının da \%1 oranında ısı değiştiricide olduğu belirlenmiştir. Sonuç olarak, R134a çalışma akışkanına alternatif olarak seçilen R1234yf akışkanının ORC sistemi için kullanılabilecek en uygun akışkan olduğu gözlemlenmiştir.

Anahtar Kelimeler: Çalışma akışkanları, ekserji, enerji, ısı değiştirici, organik Rankine çevrimi

\section{Energy and Exergy Analysis of an Organic Rankine Cycle with Internal Heat Exchanger}

\begin{abstract}
In this study, energy and exergy analysis of an organic Rankine cycle with internal heat exchanger using R1234yf, R1234ze and R134a is carried out. The energy and exergy performances of an ORC system for different operating temperature have been analyzed. It is seen from the analysis that, boiler, condenser and subcooling temperature has significant effect on both energy and exergy efficiencies. It was observed that energy and exergy efficiency increased with the increase of boiler and supercooling temperature, and energy and exergy efficiency decreased with the increase of condenser temperature. In addition, exergy destructions of each component were determined. Since the turbine and pump are considered isentropic, exergy destructions in these elements have been neglected. It was determined that the highest exergy destruction was in the condenser with the rate of $72 \%$ and the least exergy destruction was in the heat exchanger with the rate of $1 \%$. As a result, it has been observed that the R1234yf fluid chosen as an alternative to the R134a working fluid is the most suitable fluid for the ORC system.
\end{abstract}

Keywords: Working fluids, exergy, energy, heat exchanger, organic Rankine cycle 
İç Isı Değiştiricili Bir Organik Rankin Çevriminin Enerji ve Ekserji Analizi

\section{GíRiş}

Enerji, insanlığın ilerlemesi ve sosyal gelişimi için vazgeçilemeyecek bir kaynaktır. Enerji verimliliğini artırmak, küresel bir araştırma noktası haline gelmiştir. Günümüzde yüksek ısı enerjisine sahip kaynaklardan enerji elde edilmesi pek çok sistem ile sağlanabilmektedir. Ancak düşük sıcaklıklı bir kaynaktan enerji elde edebilmenin teknik ve ekonomik zorlukları oldukça fazladır (Hung ve Feng, 2019).

Organik Rankine çevrimi (ORC) uygulamaları güneş enerjisi, jeotermal enerji ve atık ısı geri kazanımı gibi düşük sıcaklıklı kaynaklardan enerji elde edebilmenin üstün teknolojilerinden biridir (Chen ve ark., 2020). ORC ve Rankine çevrimi uygulamaları arasındaki tek fark ise akışkan tercihidir. Rankine çevrimi uygulamalarında akışkan olarak su seçilirken; ORC uygulamalarında daha düşük sıcaklık ve basınç değerleri arasında çalışabilen R134a, R404a, R21 gibi akışkanlar kullanılmaktadır.

Çalışma sıvısı seçimi, kazan ve yoğuşturucudaki çalışma sıcaklıkları, iç ısı değiştiricili bir sistem kullanılıyorsa ısı değiştiricisinin etkinliği, aşırı soğutma sıcaklığı gibi faktörler ORC uygulamalarının verimliliğine etki eden en önemli parametrelerdir (Chen ve ark., 2020). Literatürde ORC ile ilgili yapılmış birçok çalışma bulunmaktadır. Son zamanlarda yapılan bu çalışmalardan bazıları Tablo 1'de verilmiştir.

Tablo 1. ORC ile ilgili yapılmış bazı çalışmalar

\begin{tabular}{lll}
\hline Kullanılan Akışkanlar & Çalışılan Konu & Yazarlar \\
\hline R123, R245fa, R600a, & Enerji ve ekserji analizi & Aghahosseini ve Dincer, 2013 \\
R134a, R407c, R404a & Enerji ve ekserji analizi & Ashouri ve ark., 2017 \\
R245fa, R134a, pentane, toluene & Enerji ve ekserji analizi & Saleh, 2018 \\
R602 & Enerji ve ekserji analizi & Acar ve Aslan, 2019 \\
R-600a & Enerji ve ekserji maliyeti & Navongxay ve Chaiyat, 2019 \\
R-245fa & Performans analizi & Hung ve Feng, 2019 \\
R123 & & \\
R134a-R32 karışımı & Dinamik davranış analizi & Chen ve ark., 2020 \\
R245fa & Verim analizi & Alvarado ve ark., 2019 \\
Farklı çalışma akışkanları & Iyileştirme & Köse ve ark., 2020 \\
R123, R245, R600 & Optimizasyon & Bademlioğlu ve ark., 2020 \\
R1234yf, R134a, R245fa, izobütan & Optimizasyon & Song ve ark., 2020 \\
& & \\
\hline Heptan-R245fa karışımı & Termodinamik analiz & Tiwari ve ark., 2020 \\
R21, R114, R245fa & Optimizasyon & Sun ve ark., 2020 \\
Toluen & Fizibilite & Pantaleo ve ark., 2020 \\
Sikloheksan & Optimizasyon & Karimi ve ark., 2020 \\
Farklı çalışma akışkanları & Akışkan seçimi & Lin ve ark., 2020 \\
R1233zd & Performans analizi & Talluri ve ark., 2020 \\
R236fa, R245fa, R1336mzz & Perfomans analizi & Yang ve ark., 2020 \\
5 farklı çalışma akışkanı & Ekserji analizi & Kavaslıoğulları ve Cihan, 2015 \\
R600a, R1234ze(Z), R1233zd(E) & Akışkan değerlendirmesi & Longo ve ark., 2020 \\
20 farklı çalışma sıvısı & Akışan seçimi & Emadi ve ark., 2020 \\
34 farklı çalışma sıvısı & Optimizasyon & Rad ve ark., 2020 \\
R245fa & Modelleme & Alvi ve ark., 2020 \\
Siloksan & Aerodinamik tasarım & Quan ve ark., 2020 \\
Toluen, benzen ve siklopentan & Performans analizi & Carcasci ve ark., 2020 \\
Farklı çalışma akışkanları & Aksşkan seçimi & Xia ve ark., 2020 \\
\hline
\end{tabular}


İç Isı Değiştiricili Bir Organik Rankin Çevriminin Enerji ve Ekserji Analizi

Tablo 1'de görüldüğü gibi ORC sistemi üzerinde pek çok deneysel ve teorik çalışma yapılmıştır. Bu çalışmada literatürden farklı olarak R134a akışkanına alternatif olarak sıfır ODP ve düşük GWP değerlerine sahip R1234yf ve R1234ze çalışma akışkanları kullanılarak iç ısı değiştiricili bir ORC sisteminin Engineering Equation Solver (EES) programı kullanılarak enerji ve ekserji analizi yapılmıştır. Isıl verim ve ekserji verimi değerlerinin farklı çaIışma parametrelerine göre değişimleri analiz edilmiştir. Ayrıca, sistemi oluşturan her bir elemana ait ekserji yıkımları belirlenerek yine farklı çalışma parametrelerine göre değişimleri incelenmiştir. Sisteme ait ekserji yıkımlarının sistem verimine etkisi incelenmiştir.

\section{MATERYAL VE YÖNTEM}

Bu çalışmada iç ısı değiştiricili ORC sisteminin R1234yf, R1234ze ve R134a akışkanları kullanılarak termodinamik analizi yapılmıştır. ORC sistemine eklenen iç ısı değiştirici sayesinde, kazanda buharın daha yüksek sıcaklıklara ısıtılması ve yoğuşturucu sıcaklığının düşürülmesi sağlanmaktadır. Böylece ORC sisteminin veriminin artııııması mümkün olmaktadır. Çalışmada kullanılan akışkan çiftleri ve özellikleri Tablo 2'de verilmiştir.

Sistem elemanlarının sıcaklık değişimleriyle ısıl ve ekserji verimlerinin değişimi incelenmiştir. Ayrıca yine çaIışma sıcaklıklarının ekserji yıkımlarına etkisi incelenmiştir. Tüm analizlerde EES programı kullanılmıştır. Şekil 1'de analizi yapılan iç ISı değiştiricili bir ORC sistemi gösterilmiştir.

Tablo 2. Çalışmada kullanılan çalışma akışkanların bazı özellikleri (Llopis ve ark., 2015)

\begin{tabular}{|l|r|r|r|r|c|}
\hline Soğutkan & $\begin{array}{c}\text { Kaynama } \\
\text { sıcaklığı } \\
\left({ }^{\circ} \mathrm{C}\right)\end{array}$ & $\begin{array}{c}\text { Kritik sıcak- } \\
\text { lık }\left({ }^{\circ} \mathrm{C}\right)\end{array}$ & $\begin{array}{c}\text { Kritik ba- } \\
\text { sınç (bar) }\end{array}$ & ODP & GWP \\
\hline R134a & -26.5 & 101.1 & 40.59 & 0 & 1300 \\
\hline R1234yf & -29.49 & 94.70 & 32.69 & 0 & 1 \\
\hline R1234ze & -18.98 & 108.0 & 35.39 & 0 & 1 \\
\hline
\end{tabular}

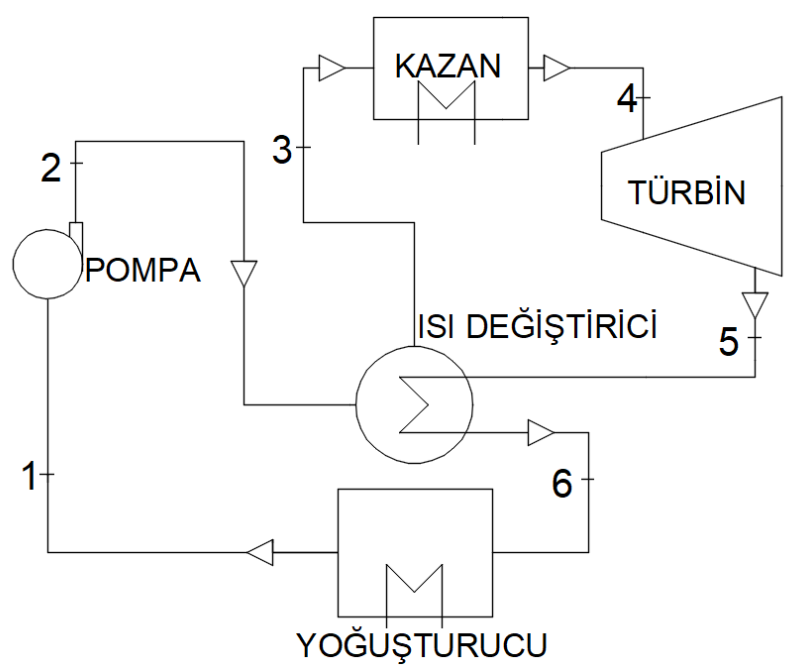

Şekil 1. İç Isı değiştiricili ORC sistemi

İç ISı değiştiricili ORC sisteminde tüm sistem elemanları sürekli-akışlı açık sistem olarak incelenmiştir. İş ve ısı geçişi baz alınarak kinetik ve potansiyel enerjilerdeki değişim oldukça küçük olduğu için inmal edilebilir. Böylece akışkanın birim kütlesi için sürekli akışı-açık sisteme ilişkin enerji korunumu denklemi aşağıdaki eşitlikle ifade edilebilir (Çengel ve Boles, 2012). Termodinamik analizlerde çevre sıcaklığı $25^{\circ} \mathrm{C}$ olarak alınmıştır.

$$
\left(\dot{\mathrm{q}}_{\mathrm{g}}-\dot{\mathrm{q}}_{\mathrm{c}}\right)+\left(\dot{\mathrm{w}}_{\mathrm{g}}-\dot{\mathrm{w}}_{\mathrm{c}}\right)=\mathrm{h}_{\mathrm{c}}-\mathrm{h}_{\mathrm{g}}
$$

Sürekli akışlı açık sistemler için ekserji dengesi aşağıdaki eşitlikle ifade edilebilir [22].

$$
\Sigma\left(1-\frac{\mathrm{T}_{0}}{\mathrm{~T}_{\mathrm{k}}}\right) \cdot \dot{\mathrm{Q}}-\dot{\mathrm{W}}+\Sigma_{\mathrm{g}} \dot{\mathrm{m}} \cdot \mathrm{Ex}-\Sigma_{\mathrm{C}} \dot{\mathrm{m}} \cdot \mathrm{Ex}-\dot{\mathrm{E}} \mathrm{x}_{\mathrm{ylklm}}=0
$$

İş ile gerçekleşen ekserji işi, işin kendisine eşittir ve aşağıdaki gibi yazılabilir.

$$
\dot{\mathrm{E}} \mathrm{x}_{\mathrm{W}}=\dot{\mathrm{W}}
$$

Isı ile ekserji geçişi ise aşağıdaki eşitlikle ifade edilmiştir (Çengel ve Boles, 2012).

$$
\dot{\mathrm{Ex}} \mathrm{Q}_{\mathrm{Q}}=\left(1-\frac{\mathrm{T}_{0}}{\mathrm{~T}}\right) \cdot \dot{\mathrm{Q}}
$$

Akış ekserjisi aşağıdaki eşitlikle ifade edilebilir (Çengel ve Boles, 2012).

$$
\dot{\mathrm{Ex}}=\dot{\mathrm{m}}\left[\left(\mathrm{h}-\mathrm{h}_{0}\right)-\mathrm{T}_{0} \cdot\left(\mathrm{s}-\mathrm{s}_{0}\right)\right]
$$

Şekil 1'de verilen iç ISı değiştiricili ORC sisteminde her bir sistem elemanına ait enerji ve ekserji dengesi Tablo 3'de verilmiştir. Iç ısı değiştiricili ideal Rankine çevriminin ısıl verimi 6 numaralı denklemde verilmiştir. 
İç Isı Değiştiricili Bir Organik Rankin Çevriminin Enerji ve Ekserji Analizi

Tablo 3. Sistem elemanlarına ait enerji ve ekserji denge eşitlikleri

\begin{tabular}{|c|c|c|}
\hline Sistem Elemanı & Enerjinin Dengesi & Ekserji Dengesi \\
\hline Pompa & $\dot{\mathrm{W}}_{\mathrm{p}}=\dot{\mathrm{m}} \cdot\left(\mathrm{h}_{2}-\mathrm{h}_{1}\right)$ & $\dot{\mathrm{E}} \mathrm{x}_{\mathrm{y} \mathrm{k} ı \mathrm{~m}, \mathrm{P}}=\dot{\mathrm{E} x_{2}}-\dot{\mathrm{E} \mathrm{x}_{1}}+\dot{\mathrm{W}}_{\mathrm{p}}$ \\
\hline Kazan & $\dot{\mathrm{Q}}_{\text {Kazan }}=\dot{\mathrm{m}} \cdot\left(\mathrm{h}_{4}-\mathrm{h}_{3}\right)$ & $\dot{\mathrm{E}} \mathrm{x}_{\mathrm{ylk} \text { Im,Kazan }}=\dot{\mathrm{E}} \mathrm{x}_{4}-\dot{\mathrm{E}} \mathrm{x}_{3}+\dot{\mathrm{E}} \mathrm{x}_{\mathrm{QKazan}_{\mathrm{Kan}}}$ \\
\hline Türbin & $\dot{\mathrm{W}}_{\mathrm{T}}=\dot{\mathrm{m}} \cdot\left(\mathrm{h}_{4}-\mathrm{h}_{5}\right)$ & $\dot{E}_{\mathrm{ylkIm}, \mathrm{T}}=\dot{\mathrm{E}} \mathrm{x}_{4}-\dot{\mathrm{E}} \mathrm{x}_{5}-\dot{\mathrm{W}}_{\mathrm{T}}$ \\
\hline $\begin{array}{l}\text { Yoğuşturucu } \\
\text { Isı değiştirici }\end{array}$ & $\begin{array}{l}\dot{\mathbf{Q}}_{\mathrm{Yoğ}}=\dot{\mathbf{m}} \cdot\left(\mathbf{h}_{6}-\mathbf{h}_{1}\right) \\
\dot{\mathbf{m}} \cdot \mathbf{h}_{2}+\dot{\mathbf{m}} \cdot \mathbf{h}_{5}=\dot{\mathbf{m}} \cdot \mathbf{h}_{3}+\dot{\mathbf{m}} \cdot \mathbf{h}_{6}\end{array}$ & $\begin{array}{l}\dot{\mathbf{E}} \mathbf{x}_{\mathbf{y l k ı m}, \mathbf{Y o g ̆}}=\dot{\mathbf{E}} \mathbf{x}_{6}-\dot{\mathbf{E}} \mathbf{x}_{1}-\dot{\mathbf{E}} \mathbf{x}_{\mathbf{Q}_{\mathrm{Yoğ}}} \\
\dot{\mathbf{E}} \mathbf{x}_{\mathbf{y} \mathbf{k} \mathbf{k}, \mathbf{l d}}=\dot{\mathbf{E}} \mathbf{x}_{2}+\dot{\mathbf{E}} \mathbf{x}_{5}-\dot{\mathbf{E}} \mathbf{x}_{3}-\dot{\mathbf{E}} \mathbf{x}_{6}\end{array}$ \\
\hline
\end{tabular}

$$
\eta=\frac{\dot{\mathrm{W}}_{\mathrm{T}}-\dot{\mathrm{W}}_{\mathrm{P}}}{\dot{\mathrm{Q}}_{\text {Kazan }}}=\frac{\dot{\mathrm{W}}_{\mathrm{net}}}{\dot{\mathrm{Q}}_{\text {Kazan }}}=\frac{\left(\mathrm{h}_{4}-\mathrm{h}_{5}\right)-\left(\mathrm{h}_{2}-\mathrm{h}_{1}\right)}{\left(\mathrm{h}_{4}-\mathrm{h}_{3}\right)}
$$

Sistemin toplam ekserji yıkımı aşağıdaki gibi hesaplanabilir.

$$
\begin{aligned}
& \dot{E} x_{\text {toplam yıkım }}=\dot{E} x_{\text {yıkım,P }}+\dot{E} x_{\text {yıkım,Kazan }}+\dot{E} x_{\text {yıkım,T }}+ \\
& \dot{E} x_{\text {ylkım,Yoğ }}+\dot{E} x_{\text {yıkım,ıd }}
\end{aligned}
$$

Sistemin ikinci yasa verimi ise aşağıdaki gibi yazılabilir.

$$
\eta_{\mathrm{E}}=\frac{\dot{\mathrm{W}}_{\mathrm{net}}}{\dot{\mathrm{E} \mathrm{x}_{1 \mathrm{S1}}}}=1-\frac{\dot{\mathrm{E}} \mathrm{x}_{\text {toplam yıkım }}}{\dot{\mathrm{E}} \mathrm{x}_{1 \mathrm{~S} 1}}
$$

\section{BULGULAR VE TARTIŞMA}

Bu çalışmada R134a, R1234yf ve R1234ze akışkanları kullanılan iç ısı değiştiricili ORC sisteminin termodinamik analizi yapılmıştır. Tüm akışkanlar için farklı kazan ve yoğuşturucu sıcaklıkları için ısıl verim ve ekserji verim değişimleri incelenmiştir. Ayrıca kazan ve yoğuşturucu sıcaklığı sabit tutularak aşırı soğutma sıcaklığının değişimine göre ısıl verim ve ekserji verim değişimleri de incelenmiştir. İç ısı değiştiricili ORC sisteminin her bir elemanına ait ekserji yıkımları belirlenmiştir.

Çalışmada kullanılan tüm akışkanların termodinamik özellikleri de EES programı kullanılarak belirlenmiştir. Örnek olarak R134a akışkanı ile çalışan iç ısı değiştiricili ORC sisteminin her noktasındaki bazı termodinamik özellikler EES programı yardımıyla hesaplanmış ve Tablo 4'de verilmiştir.

Tablo 4. R134a akışkanının kullanıldığı sistemin her noktasındaki termodinamik özellikler

\begin{tabular}{|c|c|c|c|c|c|}
\hline NOKTA & $\mathrm{h}(\mathrm{kJ} / \mathrm{kg})$ & $\begin{array}{c}\mathrm{P} \\
(\mathrm{kPa})\end{array}$ & $\begin{array}{c}\mathrm{s} \\
(\mathrm{kJ} / \mathrm{kgK})\end{array}$ & $\begin{array}{c}\mathrm{T} \\
\left({ }^{\circ} \mathrm{C}\right)\end{array}$ & $\begin{array}{c}\dot{\mathrm{Ex}} \\
(\mathrm{kW})\end{array}$ \\
\hline 1 & 93.58 & 770.60 & 0.34 & 30.00 & 22.67 \\
\hline 2 & 94.34 & 1683.00 & 0.34 & 30.54 & 23.08 \\
\hline 3 & 101.80 & 1683.00 & 0.37 & 35.72 & 25.18 \\
\hline 4 & 291.50 & 1683.00 & 0.94 & 70.00 & 33.12 \\
\hline 5 & 274.80 & 770.60 & 0.94 & 37.79 & 24.31 \\
\hline 6 & 267.30 & 770.60 & 0.92 & 30.62 & 24.19 \\
\hline
\end{tabular}

Şekil 2'de üç farklı çalışma akışkanı için $30^{\circ} \mathrm{C}$ yoğuşturucu sıcaklığı, $10^{\circ} \mathrm{C}$ aşırı kızdırma sıcaklığı ve $5^{\circ} \mathrm{C}$ aşırı soğutma sıcaklığında; beş farklı kazan sıcaklığına göre iç ISı değiştiricili ORC sisteminin ısıl verimlerindeki değişim gösterilmiştir. Şekilde görüldüğü üzere her üç akışkan için de kazan sıcaklığı arttıkça sistemin ısıl verim değerleri artmaktadır. Farklı kazan sıcaklıklarında her üç akışkanla çalışan sistemin ısıl verimlerinin 0.05 ile 0.1 arasında değiştiği ve birbirine çok yakın olduğu gözlemlenmektedir.

Şekil 3'te üç farklı çalışma akışkanı için $30^{\circ} \mathrm{C}$ yoğuşturucu sıcaklığı, $10^{\circ} \mathrm{C}$ aşırı kızdırma sıcaklığı ve $5^{\circ} \mathrm{C}$ aşırı soğutma sıcaklığında; beş farklı kazan sıcaklığına göre iç ISI değiştiricili ORC sisteminin ekserji verimlerindeki değişim gösterilmiştir. Şekilden görüldüğü üzere tüm çaıı̧̧ma akışkanları için kazan sıcaklığı arttıkça sistemin ekserji verimi artmaktadır. Ancak ekserji verimindeki bu artışın yaklaşık $60^{\circ} \mathrm{C}$ kazan sıcaklığından sonra sabit kaldığı görülmektedir. Belirlenen çalışma parametrelerinde optimum kazan sıcaklığı değerlerine yaklaşıldığı için bu değerden sonraki sıcaklık artışı, ekserji verim değerinde belirgin bir artmaya sebep olmamıştır. Ayrıca R1234yf ile çalışan sistemin ekserji verimi değerlerinin diğer çalışma akışkanlarıyla çalışan sistemin ekserji verimi değerlerinden daha yüksek olduğu görülmüştür.

Şekil 4'de $60^{\circ} \mathrm{C}$ kazan sıcaklığı, $10^{\circ} \mathrm{C}$ aşırı kızdırma sıcaklığı ve $5^{\circ} \mathrm{C}$ aşırı soğutma sıcaklığında; $25-35^{\circ} \mathrm{C}$ yoğuşturucu sıcaklık aralığında üç farklı akışkan için iç ısı 
İç Isı Değiştiricili Bir Organik Rankin Çevriminin Enerji ve Ekserji Analizi

değiştiricili ORC sisteminin ısıl verim değişimi görülmektedir. Yoğuşturucu sıcaklığının artmasıyla ısıl verim de- ğerinin azaldığı görülmektedir. Farklı yoğuşturucu sıcaklıklarında her üç akışkanla çalışan sistemin ısıl verimlerinin birbirine çok yakın olduğu görülmektedir.

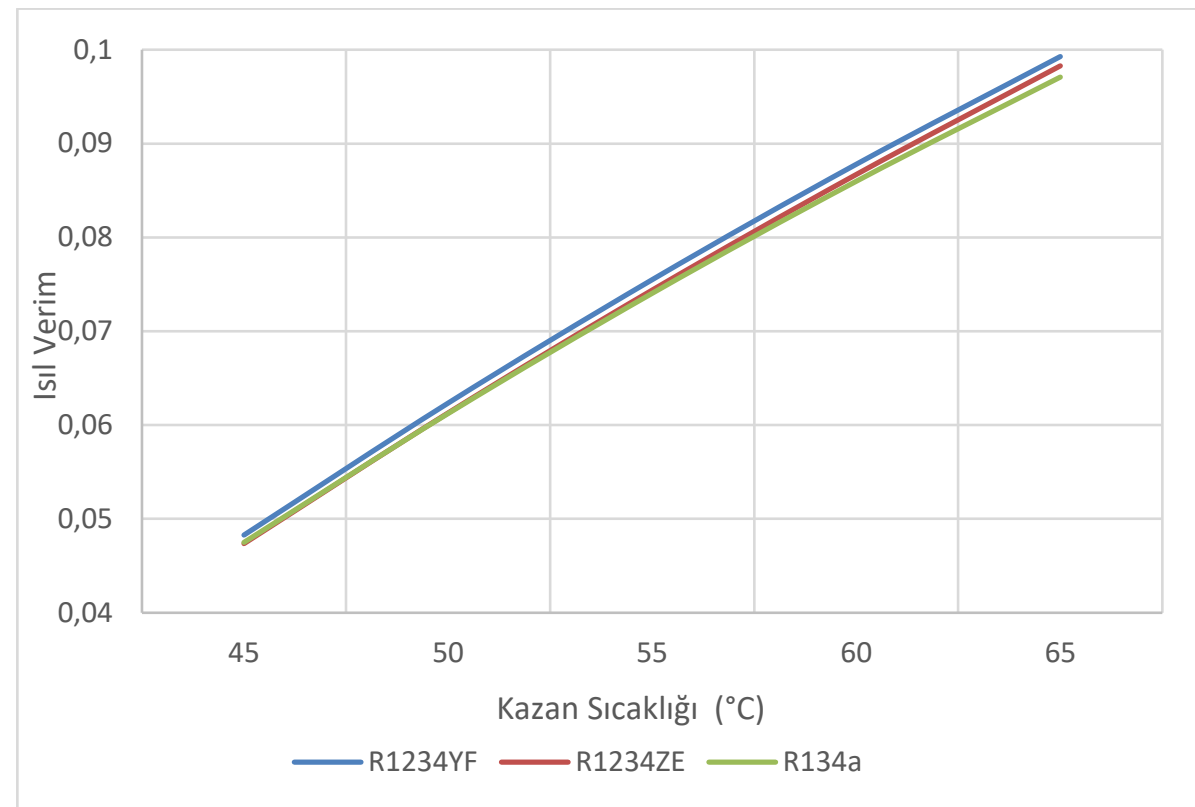

Şekil 2. Farklı kazan sıcaklıklarında ısıl verim değişimi

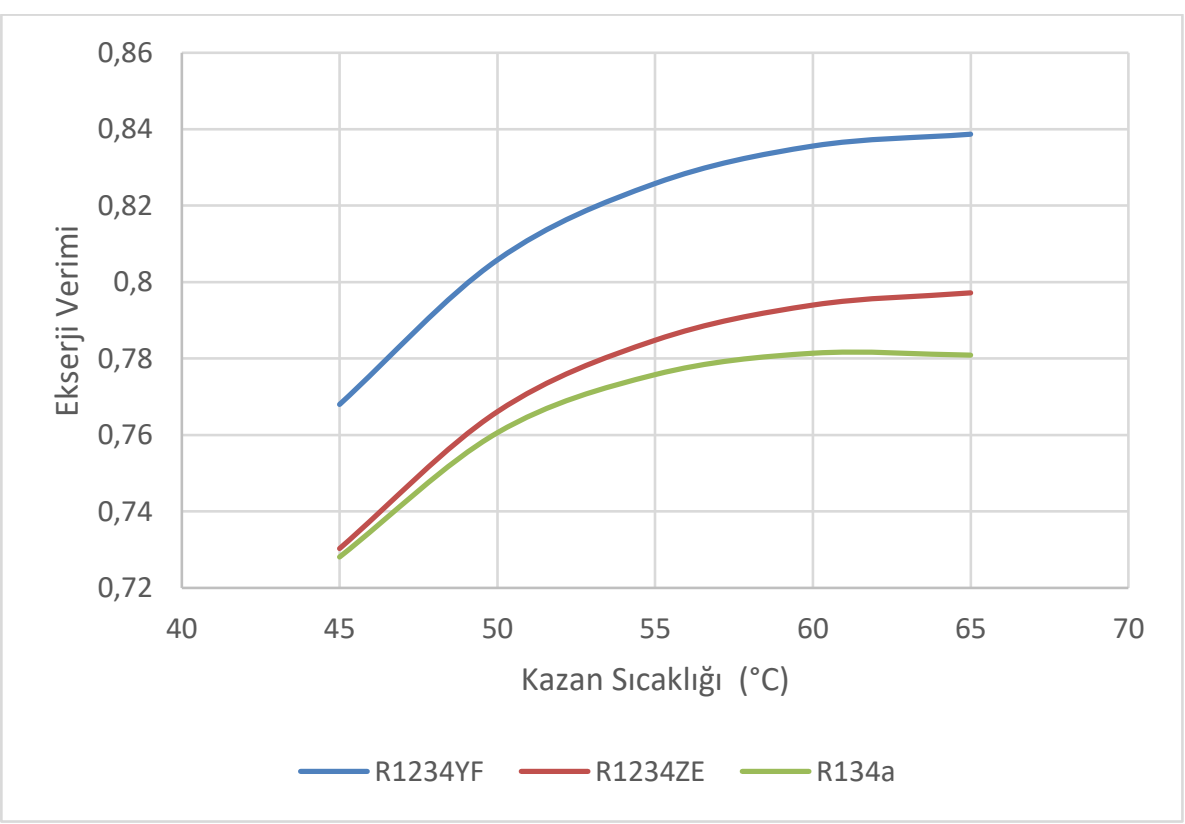

Şekil 3. Farklı kazan sıcaklıklarında ekserji verim değişimi 
İç Isı Değiştiricili Bir Organik Rankin Çevriminin Enerji ve Ekserji Analizi

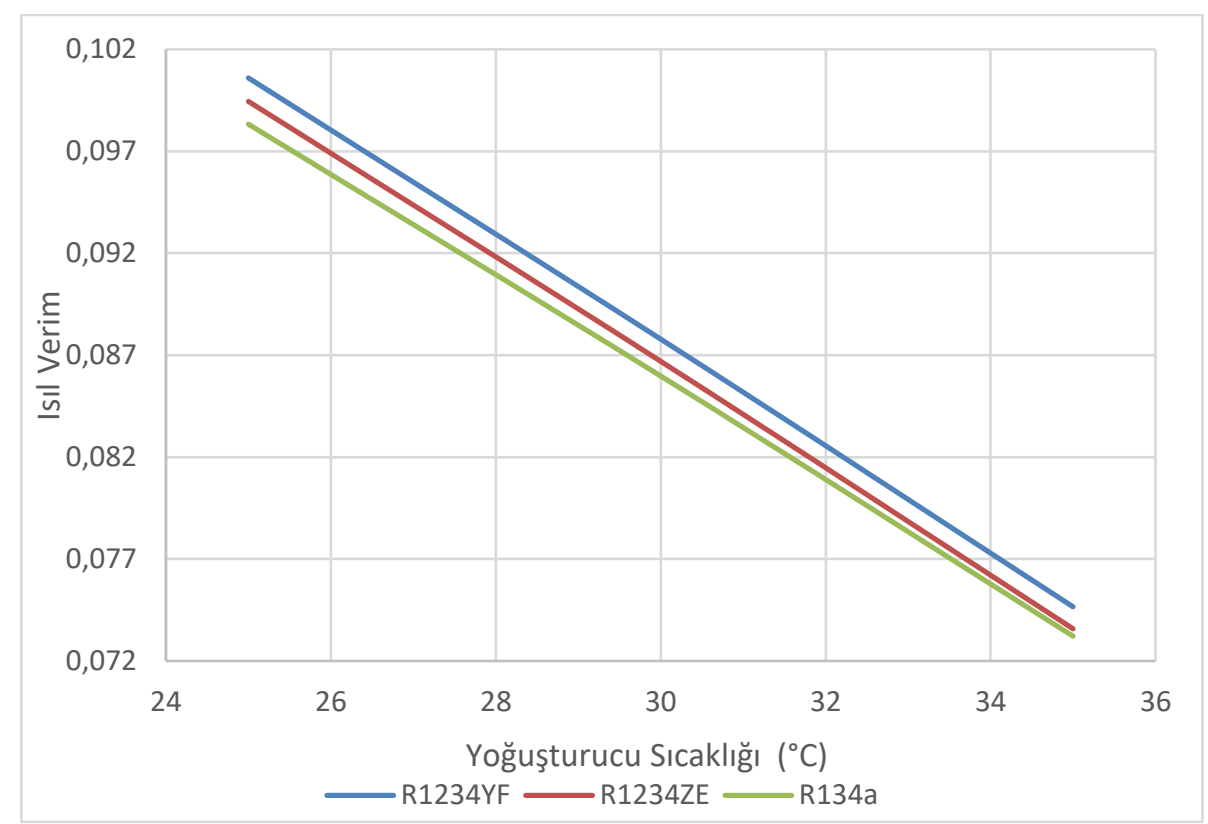

Şekil 4. Farklı yoğuşturucu sıcaklıklarında ısıl verim değiş̧imi

Şekil $5^{\prime}$ te $60^{\circ} \mathrm{C}$ kazan sıcaklığı, $10^{\circ} \mathrm{C}$ aşırı kızdırma sıcaklığı ve $5^{\circ} \mathrm{C}$ aşırı soğutma sıcaklığında; $25-35^{\circ} \mathrm{C}$ yoğuşturucu sıcaklık aralığında üç farklı çalışma akışkanı için iç ISI değiştiricili ORC sisteminin ekserji verimlerinin değişimi verilmiştir. Tüm çalışma akışkanları için yoğuşturucu sıcaklığı arttıkça ekserji verim değerleri azalmaktadır. Genel olarak R1234yf ile çalışan sistemin ekserji verim değerlerinin diğer çalışma akışkanlarıyla çalışan sistemin ekserji verim değerlerinden daha yüksek olduğu görülmüştür. Sadece $30^{\circ} \mathrm{C}$ yoğuşturucu sıcaklığında R134a akışkanıyla çalışan sistemin ekserji verimi diğer akışkanlarla çalışan sistemin ekserji verimi değerlerinden biraz daha yüksek olduğu görülmüştür.

Ayrıca aşırı soğutma sıcaklığının ısıl verim ve ekserji verim değerleri üzerine etkisi incelenmiştir. Şekil 6'da aşırı soğutma sıcaklığı arttıkça her üç çalışma akışkanı için de sistemin ısı veriminin arttığı görülmektedir. Genel olarak R1234yf akışkanının kullanıldığı sistemin ısıl verimi diğer iki akışkanın kullanıldığı sistemin ısıl veriminden daha yüksektir. Şekil 7'de aşırı soğutma sıcaklığının artmasıyla her üç akışkanla çalışan sistemin de ekserji veriminin arttığı görülmektedir. En yüksek ekserji verimine yine R1234yf akışkanı kullanılması durumunda ulaşıımıştır.

İç ISI değiştiricili ORC sistemini oluşturan her bir elemana ait ekserji yıkımları Şekil 8'de görüldüğü gibi belirlenmiştir. Türbin ve pompa izentropik kabul edildiği için bu elemanlardaki ekserji yıkımları inmal edilmiştir. Şekil 8'de görüldüğü gibi en fazla ekerji yıkımının $\% 72$ oranında yoğuşturucuda, en düşük ekserji yıkımının da \%1 oranında ısı değiştiricide olduğu belirlenmiştir. 
İç Isı Değiştiricili Bir Organik Rankin Çevriminin Enerji ve Ekserji Analizi

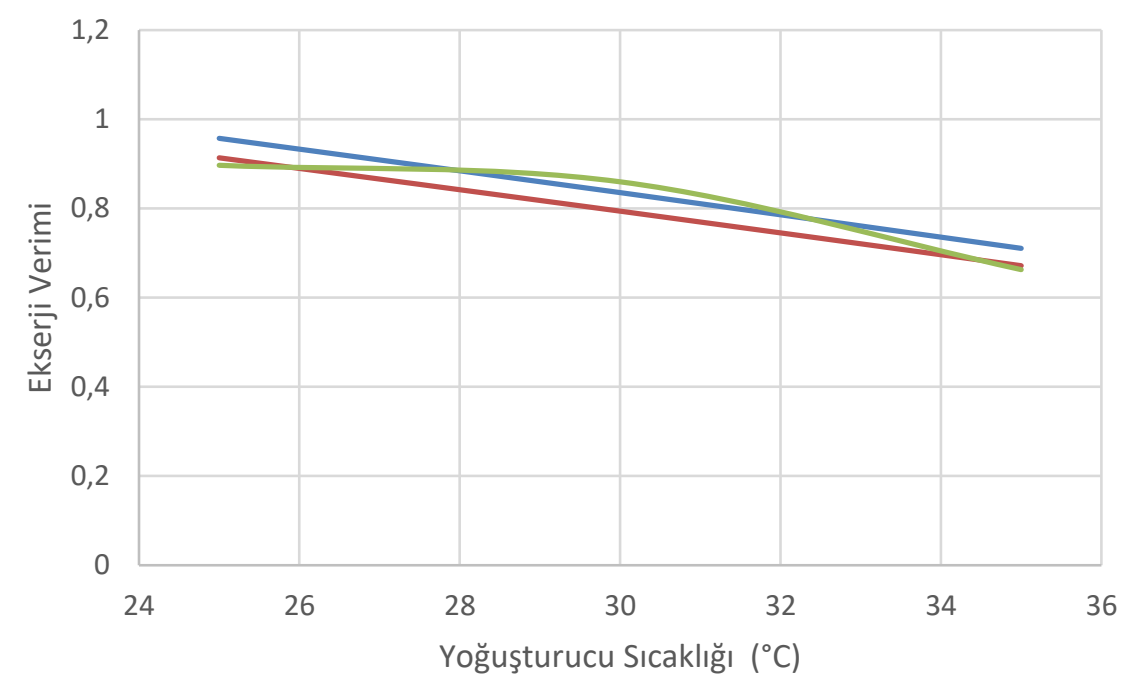

$\longrightarrow$ R1234YF R1234ZE R134a

Şekil 5. Farklı yoğuşturucu sıcaklıklarında ekserji verimi değişimi

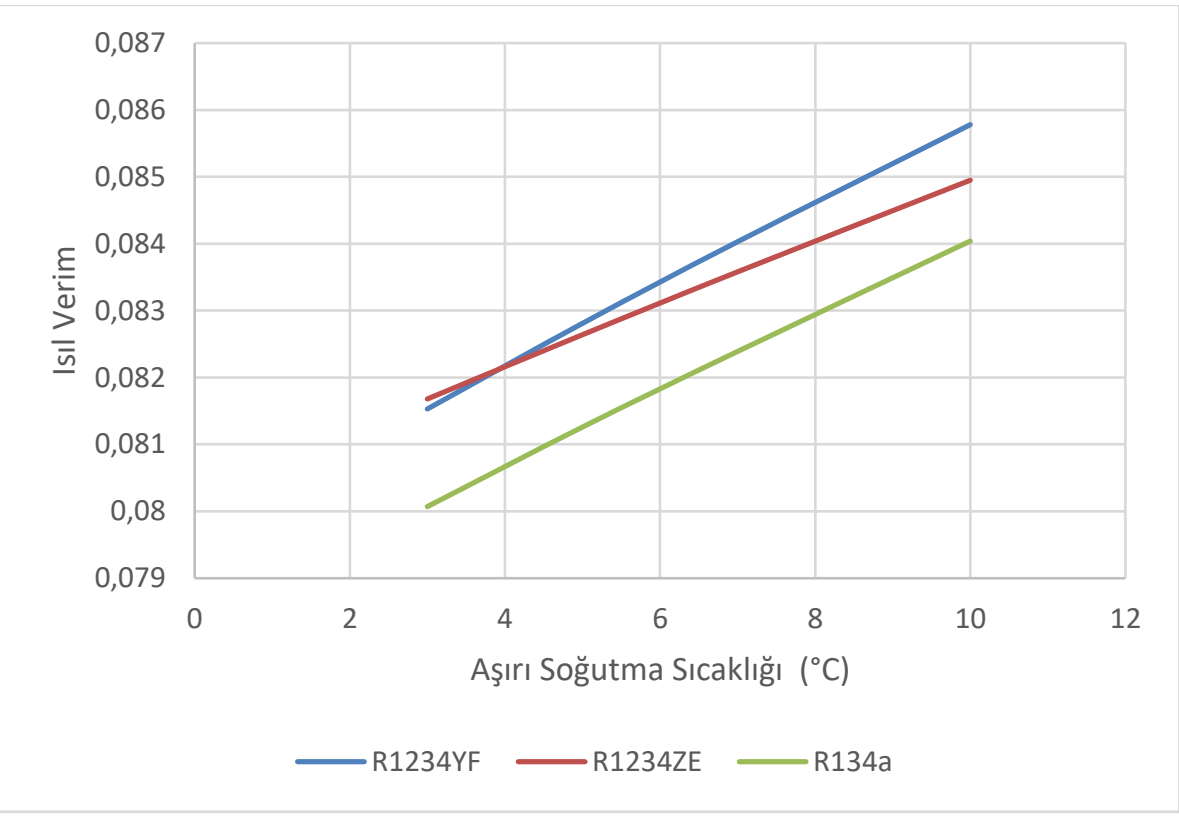

Şekil 6. Farklı çalışma akışkanları için aşırı soğutma sıcaklığının ısıl verime etkisi 
İç Isı Değiştiricili Bir Organik Rankin Çevriminin Enerji ve Ekserji Analizi

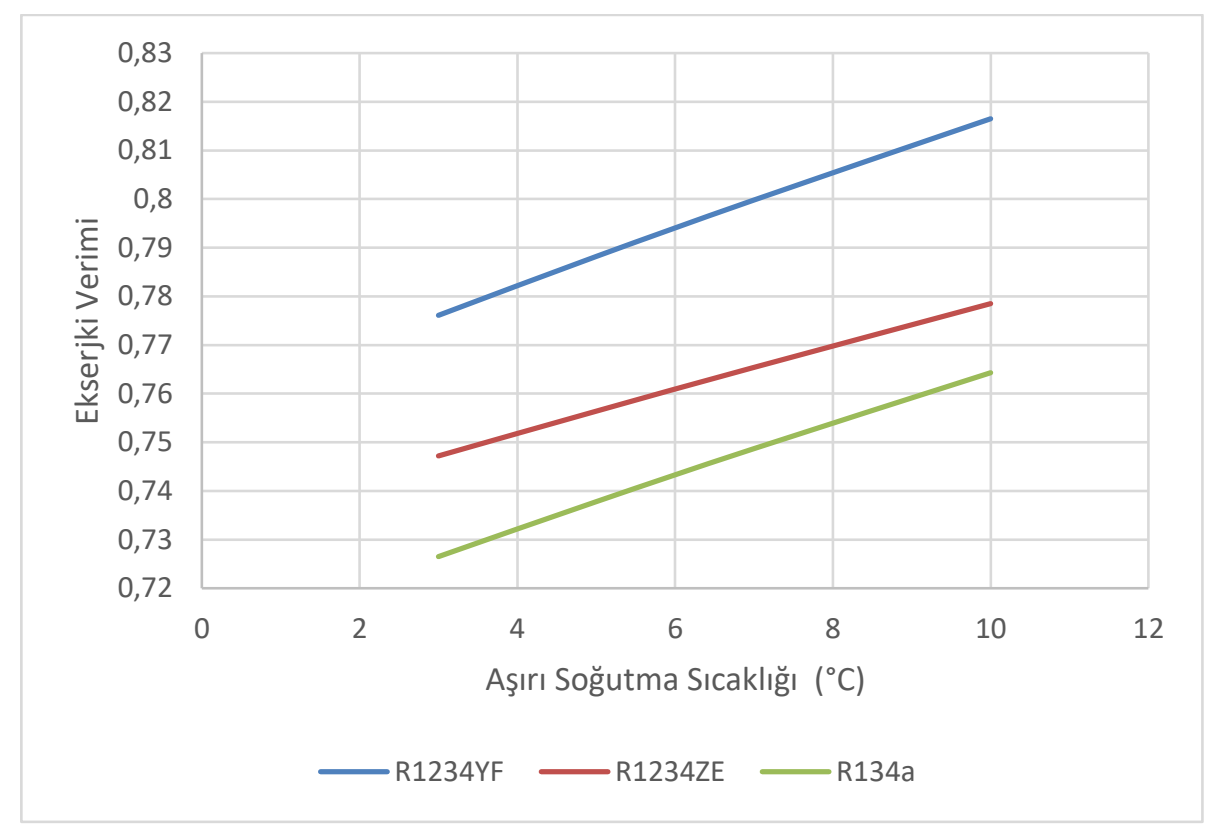

Şekil 7. Farklı çalışma akışkanları için aşırı soğutma sıcaklığının ekserji verimine etkisi

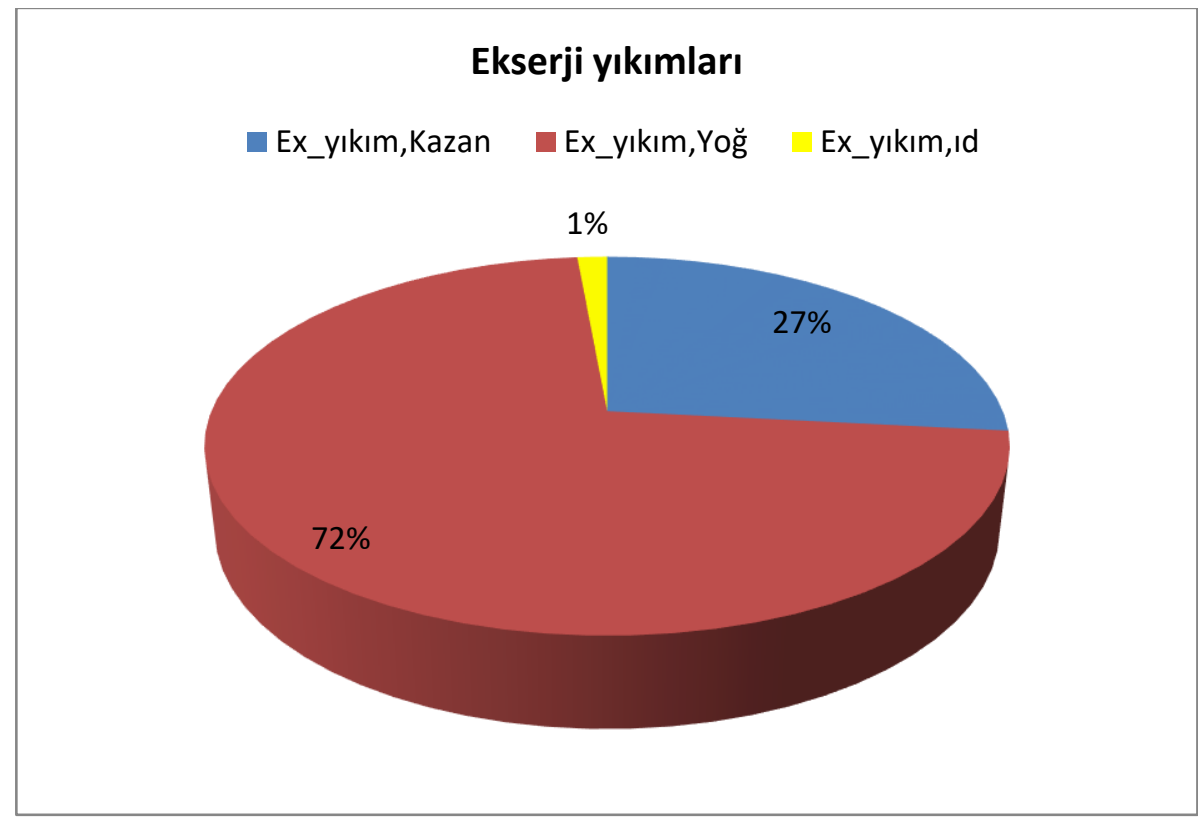

Şekil 8. ORC sistemini oluşturan her bir elemana ait ekserji yıkımları

\section{SONUÇ}

Bu çalışmada iç ısı değiştiricili bir ORC sisteminde farklı çalışma akışkanları kullanılarak ısıl verim ve ekserji verim değerlerinin değişimleri incelenmiştir.

Kazan sıcaklığının artırımasının sistem verimini olumlu etkilediği ancak belirli bir sıcaklık değerinden sonra ekserji verimini değiştirmediği görülmüştür. Yoğuşturucu sıcaklığının artmasıyla hem ısıl verim hem de ekserji verim değerlerinin azaldığı görülmüştür. Aşırı soğutma sıcaklığıyla sistemin ısıl verim ve ekserji veriminin arttığı tespit edilmiştir. Ayrıca, iç ıSı değiştiricili ORC sistemini oluşturan her bir elemana ait ekserji yıkımları belirlenmiştir. En fazla ekerji yıkımının yoğuşturucuda, en düşük ekserji yıkımının da ısı değiştiricide olduğu belirlenmiştir. ORC sisteminde çalışma akışkanının seçimi, sistemin çalışma parametrelerini ve performansını büyük ölçüde 
etkileyebilmektedir. Bu çalışmada genel olarak R134a çalışma akışkanına alternatif olarak seçilen R1234yf akışkanının iç ısı değiştiricili ORC sistemi için kullanılabilecek en uygun akışkan olduğu gözlemlenmiştir.

Çalışmadan elde edilen sonuçlar, iç ısı değiştiricili bir ORC sisteminde uygun çalışma akışkanı seçimi ve sistemin optimizasyonu konusundaki çalışmalara ve literatüre katkı sağlayacaktır.

\section{KAYNAKLAR}

Acar, M. S., Arslan, O. (2019). Energy and exergy analysis of solar energy-integrated, geothermal energy-powered Organic Rankine Cycle. Journal of Thermal Analysis and Calorimetry, 137(2): 659-666.

Aghahosseini, S., Dincer, I. (2013). Comparative performance analysis of low-temperature Organic Rankine Cycle (ORC) using pure and zeotropic working fluids. Applied Thermal Engineering, 54(1): 35-42.

Alvarez-Alvarado, J. M., Ríos-Moreno, G. J., Ventura-Ramos, E., Ronquillo-Lomelí, G., Trejo-Perea, M. (2019). Experimental Study of a 1-kW Organic Rankine Cycle Using R245fa Working Fluid and a Scroll Expander: A Case Study. IEEE Access, 7: 154515-154523.

Alvi, J. Z., Feng, Y., Wang, Q., Imran, M., Alvi, J. (2020). Modelling, simulation and comparison of phase change material storage based direct and indirect solar organic Rankine cycle systems. Applied Thermal Engineering, 170: 114780.

Ashouri, M., Ahmadi, M. H., Feidt, M., Astaraei, F. R. (2017). Exergy and energy analysis of a regenerative organic Rankine cycle based on flat plate solar collectors. Mechanics \& Industry, 18(2): 217.

Bademlioğlu, AH, Canbolat, AS ve Kaynakli, O. (2020). Taguchi-Gray İlişkisel Analizi ile Organik Rankine Döngüsü performans özelliklerini etkileyen parametrelerin çok amaçlı optimizasyonu. Yenilenebilir ve Sürdürülebilir Enerji Incelemeleri, 117: 109483.

Carcasci, C., Cheli, L., Lubello, P., Winchler, L. (2020). OffDesign Performances of an Organic Rankine Cycle for Waste Heat Recovery from Gas Turbines. Energies, 13(5): 1105.

Cengel, Y. A., Boles, M. A. (2012). Thermodynamics an Engineering Approach (Fifth ed.).

Chen, X., Liu, C., Li, Q., Wang, X., Wang, S. (2020). Dynamic behavior of supercritical organic Rankine cycle using zeotropic mixture working fluids. Energy, 191: 116576.

Emadi, M. A., Chitgar, N., Oyewunmi, O. A., Markides, C. N. (2020). Working-fluid selection and thermoeconomic optimisation of a combined cycle cogeneration dual-loop organic Rankine cycle (ORC) system for solid oxide fuel cell (SOFC) waste-heat recovery. Applied Energy, 261: 114384.

Hung, T. C., Feng, Y. Q. (2019). The Development and Application of a Small-Scale Organic Rankine Cycle for Waste Heat Recovery. In ORC for Waste Heat Recovery Applications. IntechOpen.

Karimi, M. H., Chitgar, N., Emadi, M. A., Ahmadi, P., Rosen, M. A. (2020). Performance assessment and optimization of a biomass-based solid oxide fuel cell and micro gas turbine system integrated with an organic Rankine cycle. International Journal of Hydrogen Energy, 45(11): 6262-6277.

Kavasoğulları, B., Cihan, E. (2015). Organik Rankine Çevrimi (ORC) ile Birlikte Çalışan Buhar Sıkıştırmalı Bir Soğutma Çevriminin Ekserji Analizi. Tesisat Mühendisliği, (150):7485.

Köse, Ö., Koç, Y., Yağlı, H. (2020). Performance improvement of the bottoming steam Rankine cycle (SRC) and organic Rankine cycle (ORC) systems for a triple combined system using gas turbine (GT) as topping cycle. Energy Conversion and Management, 211: 112745.

Lin, S., Zhao, L., Deng, S., Zhao, D., Wang, W., Chen, M. (2020). Intelligent collaborative attainment of structure configuration and fluid selection for the Organic Rankine cycle. Applied Energy, 264: 114743.

Llopis, R., Sánchez, D., Sanz-Kock, C., Cabello, R., Torrella, E. (2015). Energy and environmental comparison of twostage solutions for commercial refrigeration at low temperature: fluids and systems. Applied Energy, 138: 133-42.

Longo, G. A., Mancin, S., Righetti, G., Zilio, C., Brown, J. S. (2020). Assessment of the low-GWP refrigerants $R 600 a$, R1234ze (Z) and R1233zd (E) for heat pump and organic Rankine cycle applications. Applied Thermal Engineering, 167: 114804.

Navongxay, B., Chaiyat, N. (2019). Energy and exergy costings of organic Rankine cycle integrated with absorption system. Applied Thermal Engineering, 152: 67-78.

Pantaleo, A. M., Camporeale, S. M., Sorrentino, A., Miliozzi, A., Shah, N., Markides, C. N. (2020). Hybrid solar-biomass combined Brayton/organic Rankine-cycle plants integrated with thermal storage: Techno-economic feasibility in selected Mediterranean areas. Renewable Energy, 147: 29132931.

Quan, Y., Liu, J., Zhang, C., Wen, J., Xu, G., Dong, B. (2020). Aerodynamic design of an axial impulse turbine for the high-temperature organic Rankine cycle. Applied Thermal Engineering, 167: 114708.

Rad, E. A., Mohammadi, S., Tayyeban, E. (2020). Simultaneous optimization of working fluid and boiler pressure in an organic Rankine cycle for different heat source temperatures. Energy, 194: 116856.

Saleh, B. (2018). Energy and exergy analysis of an integrated organic Rankine cycle-vapor compression refrigeration system. Applied Thermal Engineering, 141: 697-710.

Song, J., Loo, P., Teo, J., Markides, C. N. (2020). ThermoEconomic Optimization of Organic Rankine Cycle (ORC) Systems for Geothermal Power Generation: A Comparative Study of System Configurations. Frontiers in Energy Research, 8: 6.

Sun, Q., Wang, Y., Cheng, Z., Wang, J., Zhao, P., Dai, Y. (2020). Thermodynamic and economic optimization of a double-pressure organic Rankine cycle driven by low-temperature heat source. Renewable Energy, 147: 28222832.

Talluri, L., Dumont, O., Manfrida, G., Lemort, V., Fiaschi, D. (2020). Experimental investigation of an Organic Rankine Cycle Tesla turbine working with R1233zd (E). Applied Thermal Engineering, 115293.

Tiwari, D., Sherwani, A. F., Atheaya, D., Kumar, A., Kumar, N. (2020). Thermodynamic analysis of Organic Rankine cycle 
İç Isı Değiştiricili Bir Organik Rankin Çevriminin Enerji ve Ekserji Analizi

driven by reversed absorber hybrid photovoltaic thermal compound parabolic concentrator system. Renewable Energy, 147: 2118-2127.

Xia, X. X., Wang, Z. Q., Zhou, N. J., Hu, Y. H., Zhang, J. P., Chen, Y. (2020). Working fluid selection of dual-loop organic Rankine cycle using multi-objective optimization and improved grey relational analysis. Applied Thermal Engineering, 171: 115028.

Yang, M. H., Yeh, R. H. (2020). Optimum composition ratios of multicomponent mixtures of organic Rankine cycle for engine waste heat recovery. International Journal of Energy Research, 44(2): 1012-1030. 